\title{
MANUSCRIPT
}

\section{“I Don't See That as a Medical Problem”: Clinicians' Attitudes and Responses to Requests for Cosmetic Genital Surgery by Adolescents.}

\section{Abstract}

Background: Labioplasty is a form of genital surgery to reduce large or protruding labia minora. Internationally, the rates of this surgery among women and girls is increasing and is viewed as a worrying trend. Currently, the main clinical strategy is to reassure adolescents that they are normal by talking about the variation of labia size and appearance and showing pictures demonstrating the wide range of normal female genital appearance. For the most part, policy documents recommend against labipolasty in adolescents, claiming that it is medically non-essential surgery. In this paper, we contrast findings from our interviews with clinicians with the existing literature and policy documents and we point out areas needing more thought.

Methods: This is qualitative research using semi-structured interviews. We set out to find out on what basis clinicians decide how to treat or manage adolescent patients seeking labioplasty. We interviewed clinicians who are likely to be approached by under 18s requesting labioplasty. We use interpretive content analysis and thematic analysis to analyse the data.

Results: Our findings support the emphasis on education and reassurance as the first step for all patients, but other issues that have not figured previously in the literature, that would alter clinical strategies for managing patients come out as well. Key findings are that reassurance does not always work and that the distinction 
between functional and appearance concerns is not a solid foundation in itself for deciding whether surgery is ethically appropriate.

Conclusions: We conclude that the distinction between functional and appearance concerns is not ethically relevant. It is open to different interpretations and is not regarded by all clinicians as the definitive factor in relation to surgery. The focus of clinicians should be on relieving distress whatever the cause. Appearance reasons may sometimes justify surgery but also, functional reasons may sometimes not be sufficient justification for surgery.

Keywords: Adolescent; Surgery; Genitalia, female; Bioethics. 


\section{Introduction}

Increasing numbers of women and girls are seeking genital cosmetic surgery. This is happening in Australia, the United Kingdom and the United States. In 2013 in the United States, labioplasty (a form of genital surgery) increased $44 \%$ on the previous year. Of the 5070 labioplasty procedures performed in 2013 , the highest number (51\%) were in 19-34 year olds and $158(3.1 \%)$ were in females under 18 (American Society for Aesthetic Plastic Surgery 2014a, 138; 2014b, 12). By 2015, labioplasty procedures in females under 18 increased to 400 (4.6\%) (American Society for Aesthetic Plastic Surgery 2016, 16). In Australia, Medicare data shows that the rate of Female Genital Cosmetic Surgery has more than doubled over the past decade with the biggest increase among 15 to 24 year olds (Deans et al. 2011). In the 15-24 age group, it went from 132 in 2004 to 315 in 2014 (Australian Government 2015). The trend in the UK is similar (Deans et al. 2011). The number of genital surgeries in all three countries are likely to be an underestimation because not all data is publicly available (Braun 2010, 19; Deans et al. 2011).

According to the literature, women and girls request labioplasty for appearance, functional or psychological reasons. These reasons include physical discomfort from rubbing and chaffing, sexual problems, comments or teasing by others, poor selfesteem and self-perceived unattractiveness. (Creighton 2014; Deans et al. 2011; Goodman 2011; Liao and Creighton 2007; Liao, Michala, and Creighton 2010; Liao, Taghinejadi, and Creighton 2012; Reddy and Laufer 2011). Mothers requesting 
labioplasty for teenage daughters because the mother thinks there is something wrong with the daughter's genitals is also mentioned (McQuillan, Jayasinghe, and Grover 2014). There are a small number of publications that specifically address labioplasty in adolescents (Jothilakshmi et al. 2009; Lynch, Marulaiah, and Samarakkody 2008; Michala, Koliantzaki and Antsaklis 2011; Reddy and Laufer 2011; Runacres and Wood 2016; Hamori 2016) but for the most part, women and girls are grouped together in the medical literature on labioplasty or Female Genital Cosmetic Surgery.

The increasing prevalence of Female Genital Cosmetic Surgery in adolescents is seen as worrying (British Society for Paediatric \& Adolescent Gynaecology 2013) and has been described as a "disturbing trend" (Runacres and Wood 2016, 218). This view seems to have become the standard one, although there is one article that briefly expresses support for teen labioplasty in some circumstances such as when there is "significant distress about the appearance" of the labia, the young woman understands the risks and has parental consent (Hamori 2016). Overall, there has been no sustained ethical analysis published, nor any discussion of ethical complexities and little acknowledgment of nuances in actual clinical situations. For the most part, the current discourse about adolescent labioplasty appears to be characterised by unreflective and unchallenged framing of the issues, and an associated orthodox position, as we will demonstrate further below. The purpose of this paper is to contribute a more fine-grained and ethically nuanced analysis, and to open up space for the ethical issues to be examined impartially, on their merits. We do this by firstly critically analysing the current literature on adolescent labioplasty, and then reporting and discussing findings from our empirical study of how clinicians think ethically about adolescent patients requesting labioplasty. This approach is 
important for two reasons. Firstly, it provides systematically collected data about the thinking of clinicians who have direct experience of this "disturbing trend", as an anchor point; and secondly, it provides a space in which to consider whether the ethical issues are really so straightforward as the current literature presents. In the end, we argue that the standard ways of thinking about the ethics of labioplasty for adolescents are inadequate to meet the realities of the clinical setting, and that more nuanced ethical analysis and guidance for clinicians is needed.

\section{Critical Analysis of Current Literature on Adolescent Labioplasty}

It is acknowledged in the medical literature that there is currently a lack of scientific knowledge about the development of the external female genitalia, particularly the labia minora (Michala, Koliantzaki and Antsaklis 2011; Lloyd et al. 2005, 643-644). According to Lloyd et al, there are "surprisingly few descriptions of normal female genitals in the medical literature" (Lloyd et al. 2005, 644). There is also little knowledge about the development of the external genitalia and labia minora during puberty, because it has not been formally studied (Michala, Koliantzaki and Antsaklis $2011,155)$. With concern about the increase in female genital cosmetic surgery, the literature is pre-occupied with what constitutes "normal" genital appearance and dimensions (Harding et al. 2015; Royal Australian College of General Practitioners 2015; Runacres and Wood 2016). Research has been undertaken to obtain measurements from female cadavers to "establish the range of normal vulval measurements" in order to assess the "need for labioplasty" (Runacres et al. 2015). This focus on the normal seems to imply that abnormality is the key ethical criterion: that labioplasty for adolescents would be ethically justified in cases where the labia 
were outside the (statistically) normal size range. However, none of the authors offer any reason why normalcy in this sense should have any ethical significance. It seems to be simply taken for granted.

In the bioethics literature, there is currently one article (Boraei et al, 2008), that directly addresses the ethics of labioplasty in adolescents (other than a previous paper of ours (Spriggs and Gillam 2016)). While they do discuss normalcy, Boraei et al recommend against labioplasty in adolescents for two other reasons, both explicitly ethical in nature but both not carefully enough considered. One reason is doubt about the decisional capacity of adolescents: "there is recognition that children are less able than adults to make important decisions that could affect their health for the rest of their lives" (Boraei, Clark, and Frith 2008, 40). The short-coming here is misunderstanding the consent situation. The decision of an adolescent does not have to be relied upon to ethically justify labioplasty, because the adolescent's parents could be the decision-makers for this procedure, as for any other medical procedure, based on their view of what is their child's interests. The other reason given against adolescent labioplasty is a risk/benefit comparison: there are no established benefits and there is risk of "demonstrable" harm (Boraei, Clark, and Frith 2008, 40-41). Again, however, there is a shortcoming. The authors do not provide evidence for this 'demonstrable' harm, but rather infer that it will happen, by drawing on reported harms of genital surgery done in infancy for intersex conditions. The differences between the two situations are so significant as to make this comparison invalid. In particular, surgery done in infancy clearly is not wanted by the infant, and does not address the infant's own concerns and wishes, whereas adolescents request labioplasty themselves, on the basis of their own strongly-felt 
concerns, so inference about psychological harms is invalid. Further, reported physical damage and loss of sexual sensation in the intersex context are the outcomes of now-outdated surgical techniques that were used decades ago. This evidence does not provide any sound basis for predicting similar effects from current surgical techniques, performed on much older patients.

\section{Current Policy and Clinical Recommendations}

There are a number of professional position statements which provide guidance to clinicians for management of adolescents requesting labioplasty. Some are adolescent-specific, others address adult women and adolescents as a single group. The 2013 UK guideline produced by the British Society for Paediatric \& Adolescent Gynaecology (BritSPAG) says: "In the absence of identifiable disease and until the evidence demonstrates to the contrary, labioplasty should not be performed on girls under the age of 18 years" (BritSPAG 2013, 2). The North American Society for Pediatric and Adolescent Gynecology (NASPAG) in 2011 said that surgery can be done as a last resort for "structural abnormalities" but "not for pure cosmetic issues" (Reddy and Laufer 2011, 53). The American College of Obstetricians and Gynecologists (ACOG) Committee on Adolescents (2016) is more open, saying that surgery can be "considered" for persistent psychological or emotional concerns; thereby not limiting consideration of surgery to structural abnormalities or disease (ACOG 2016, e139, e138).

The UK Royal College of Obstetricians (RCOG) in a non-adolescent specific document, says "FGCS should not normally be carried out" on girls under 18 years of age, but concludes that there is not a strong enough reason to ban the procedure 
for any age group (RCOG Ethics Committee 2013, 6-8). The Society of Obstetricians and Gynaecologists of Canada (SOGC) recommends no surgery before the patient has reached "complete maturity, including genital maturity", suggesting 16 as the lower age at which this could occur (SOGC 2013, e4). The Royal Australian and New Zealand College of Obstetricians and Gynaecologists (RANZCOG) does not make any specific reference to adolescents (RANZCOG 2016). A Royal Australian College of General Practitioners (RACGP) resource for general practitioners and other health professionals to manage requests for FGCS addresses adolescent requests by reproducing the BritSPAG recommendations against labioplasty (RACGP 2015, 12).

A set of common themes is notable in these documents. All statements recommend that doctors should respond to requests by providing an explanation that there is a large variation in appearance of female genitalia, even though some of them acknowledge that little is actually known about normal genital development or appearance (BritSPAG 2013; RACGP 2015; RCOG Ethics Committee 2013; SOGC 2013). Some guidelines specifically frame this approach as providing "reassurance" to patients that their genitals are "normal". According to ACOG: "A patient's concern regarding the appearance of her genitalia may be alleviated by a frank discussion of the wide range of normal genitalia and reassurance that the appearance of the external genitalia varies significantly from woman to woman" (ACOG 2007). Another standard feature is a statement that there is no credible evidence that labioplasty is an effective form of management: "No controlled evaluation of short and long term clinical effectiveness can be identified in the literature" (BritSPAG 2013, 6). "Absence of data supporting the safety and efficacy of these procedures makes their recommendation untenable" (ACOG 2007). 
These policy documents typically distinguish between structural problems/disease, and normal structure and size which the patient happens to have concerns about. In relation to patient concerns, they also distinguish between "functional" concerns ("chaffing" being the most commonly given example) and "appearance" concerns. Functional concerns are regarded as more legitimate and less problematic than the appearance concerns. For instance, ACOG bases the "need for surgical intervention" on "physical signs or symptoms" (ACOG 2007, 737). It includes "chronic irritation" in the class of "medically indicated" surgeries whereas surgeries to enhance appearance are not included (ACOG 2007, 737). RCOG concludes that labioplasty for "purely aesthetic reasons" raises serious ethical concerns whereas "functional" problems "do not give rise to any special ethical concerns beyond those that arise for any surgical procedure" (RCOG Ethics Committee 2013, 7). NASPAG and BritSPAG base their recommendations on this distinction.

Evidence of the uncritical orthodoxy which we referred to earlier can be seen in these guidelines. All of them refer to and/or draw heavily on a single publication "Female genital appearance: 'normality' unfolds" (Lloyd et al. 2005). This is a study that uses photography and measurements of the external genitalia of women having gynaecological procedures under general anaesthetic, to describe the "variations in genital dimensions of normal women" (Lloyd et al. 2005, 643). The study is based on the reasoning that information about "normal" female genital appearance and dimensions are "crucial" for carrying out surgery and assessing outcomes. This paper appears to be the sole source of the key common themes in the guidelines. A further worrying feature of the heavy reliance on this paper is its assumptions about the reasons why women seek surgery to alter the appearance of their genitals. 
Women's reasons are described as "far from understood", but nevertheless

attributed to an underlying desire for normalcy:

implicit in a woman's desire to alter genital appearance may be the belief that her genitals are not normal, that there is such a thing as normal female genital appearance, that the operating surgeon will know what this is, that he or she will be able to achieve this for her and that this would somehow improve her wellbeing or relationships with others (Lloyd et al. 2005, 643).

Women are also portrayed as seeking surgery as an easy solution, a pejorative interpretation with absolutely no evidential basis.

Thus, in the future, more women may request genital surgery because a solution involving experts with minimal personal responsibility is more appealing than a personal commitment to problem solving (Lloyd et al. 2005, 645).

Overall, then, the rather sparse literature is uncritical and assumption-laden, with considerable referencing of a very limited number of sources. This contributes to the entrenching of unreflective positions mentioned above. We are not alone in noting the lack of evidence underpinning policy documents and unreflective positions: "[a]uthors, even those with impeccable academic credentials, have displayed bias in their editorial and position statements" (Goodman et al. 2016; Goodman 2017, 335). In this paper, we aim to expand the discussion in the literature beyond existing narrow parameters.

To clarify the scope of this paper, we note that we are discussing FCGS, not female genital cutting commonly referred to as Female Genital Mutilation (FGM). Although FGM is sometimes equated with FGCS (Dorneles de Andrade 2010), like some others, we take the view that these practices are ethically different (Berer 2010; Kelly and Foster 2012; Nuffield Council on Bioethics 2017, 20). Even though the two practices both refer to social norms about the aesthetics of genital 
appearance, the key ethical difference is the source of motivation for the procedure. FGCS is an individual patient-initiated procedure. Adolescents requesting labioplasty want the procedure and by definition, a key feature of a cosmetic surgical procedure is that the intention is to achieve what the patient "perceives to be a more desirable appearance" or a boost to the "patient's self-esteem" (Medical Board of Australia 2015, 7). FGM, on the other hand is not done to address the girl's concern about her own appearance and she has no part in decision making. The motivation for FGM is to enforce cultural norms or attitudes. It is beyond the scope of this paper to defend this distinction in more detail; but see our discussion of broader social and conceptual issues (Spriggs and Gillam 2016; Spriggs 2016). Most importantly, we note that this paper addresses FGCS as generally understood by the profession which actually does the procedures in question. This paper refers only to adolescent cosmetic labioplasty or FCGS, terms which we use as equivalent, and not to FGM.

\section{Empirical Study of Clinicians' Response to Requests for Adolescent Labioplasty}

\section{Methods}

We investigated how clinicians think about and respond to adolescents' requests for labioplasty using qualitative research methods. As the aim was to find out on what basis clinicians decide how to treat or manage adolescent patients requesting labioplasty, we purposively sampled medical specialists who are likely to receive requests by under 18 s for FGCS. We aimed for a sample size large enough to provide rich data for meaningful analysis, where the data would allow us to approach saturation in analysis. We invited Australian cosmetic surgeons, plastic surgeons, 
gynaecologists and General Practitioners (GPs) by email or letter. To obtain a broad sample, we included any clinicians likely to be approached by under $18 \mathrm{~s}$ about FGCS, not just those who actually perform the surgery. We sent out email and letter invitations to individual practitioners and clinics using telephone directory listing. We also sent information via professional organisations, e.g. via their publicly available membership lists, electronic newsletters and professional conferences via conference organisers.

Data collection was by semi-structured interview. The interview questions were informed by our review of the FGCS literature and by broader ethical debates relevant to appearance-altering surgery. We asked clinicians how they respond to requests about FGCS by under 18s, reasons given by patients for their requests, what they are trying to find out when deciding whether to do the surgery or not and whether they have ethical concerns about FGCS in under 18s

In addition to the interview questions about participants' clinical experience, we also sought clinicians' views on three hypothetical scenarios. We asked how they would manage the following situations: (i) a mother requesting labioplasty for a 15year-old; (ii) a 13-year-old with symptoms suggestive of Body Dysmorphic Disorder who was requesting labioplasty; and (iii) a 16-year-old with what seems to be a compelling case for labioplasty, i.e. physical symptoms preventing normal activity, with no emotional or behavioural issues. Hypothetical scenarios prompt further discussion by participants in that they provide a "distancing effect", allowing participants to talk more openly (Ulrich and Ratcliffe 2008, 177), which suited our aim of investigating clinicians' thinking, rather than simply their practices. 
All interviews were conducted by MS in person or by phone, were digitally recorded with the consent of the participants and were transcribed verbatim by a professional transcriber. Data was analysed using inductive content analysis to clarify content categories and thematic analysis to identify main issues and themes (Hansen 2006; Manning and Cullum-Swan 1994; Strauss and Corbin 1990). Coding schemata were discussed and agreed on by both authors prior to final coding. Analysis of transcripts indicated that our sample size of 11 clinician participants was sufficient to allow meaningful analysis for the purposes of our research question, although saturation was not fully reached.

Data is reported as verbatim quotes. Participants are denoted by study number and specialty. Throughout the interviews, questions were about adolescents. In some instances, participants seemed to be talking generally about young women rather than under 18 s specifically. We have not included these comments in the reported findings where age is crucial to interpretation of the participant's comments.

This study was approved by <institutional name deleted for peer review> The study was carried out in accordance with COREQ criteria for qualitative research (Tong, Sainsbury, and Craig 2007).

\section{Results}

In total we recruited and interviewed eleven clinicians (five females and six males), made up of seven gynaecologists, two cosmetic surgeons, one plastic surgeon and one sexual health physician. No GPs responded. Interviews ranged from 26 to 45 minutes with an average of 35 minutes. 
What Sort of Requests are Received for Adolescent Labioplasty?

All participants reported that they had received requests for labioplasty from under 18s. Patients generally came with a referral from a GP, but not always, particularly when they consulted a plastic or cosmetic surgeon. According to one cosmetic surgeon, one third come with a referral but the other two thirds are "straight off the street" (11CS). In most cases, adolescents attended with their mothers, some came alone and one participant referred to a girl who came with her boyfriend (10PS). In the experience of the clinicians, it is usually the adolescent, but sometimes the mother, who initiates the request. An example is a mother noticing the labia minora "sticking out" when her daughter is "having a shower or when she's got no clothes on and will be concerned that there's something wrong" (4G). Clinicians reported that some patients were not seeking labioplasty per se, but rather reassurance (1CS; 4G; 5G; 6G; 9SH): "there are some that are referred that in the end are predominately seeking reassurance that everything is normal" (6G)

The reasons which the clinicians reported the adolescents as giving for their concerns included: "visual appearance" (8G); "[t]hey hated the look. Too big" (2G); "her look was completely asymmetrical” (7G); ‘... left labia minora in this girl was grossly hypertrophied ... so she couldn't ride a horse, ride a bike without extreme discomfort ...' (3G); “... functional, as in they're so big that they're visible in pants and uncomfortable in pants, they interfere with the urinary flow" (10PS); “ ... uncomfortable in clothes and couldn't wear tight jeans” (1CS); “... irritation, pain, burning, rubbing, interfering with the things that they want to do ... usually quite active young women who do competitive sport, where it really is interfering" (8G). 
one participant noted that patients' stated reasons may not reflect their actual reasons:

... a lot of them know that they have to give a story ...if they came and said I just don't like the way that it looks, that's not going to fly in a public hospital ... there's enough out there to know that that's not the story you give in a public hospital. They usually come saying that there's some sort of issue with it but some do say that they're just not happy with it (9SH).

\section{How Clinicians Responded to Requests}

\section{Initial Responses}

All participants, except one, expressed the view that when an adolescent presents with her mother, the clinician should speak to the daughter on her own so that she can speak for herself and in private. They generally ask the mother to leave the room. The one clinician who did not talk about speaking to the daughter separately was not a dissenting view. This clinician held the view that unless there was a congenital abnormality, labia that are larger than average are not a problem during adolescence, so his focus was on reassurance for both the patient and her mother, not on speaking to the adolescent on her own (7G).

Most clinicians reported that they respond to patients' concerns about their genital appearance by explaining the variation and diversity in genital appearance and trying to reassure them that they are normal. One noted that "there's such a huge range of normal genital appearance ..." (1CS), and explained that he "always" tells patients that they are "normal" and reinforces that "they don't need to do anything" (1CS). Another reported that she sees her role as one of reassuring patients "that they're normal or that they're not abnormal rather than saying that this is a problem that needs to be fixed" (5G). Another discussed with the adolescent 
"what's normal and where she fits into the normal range and that I think she is normal ...that is if they are normal of course ..." (4G).

In order to educate the adolescent about female genitalia and the wide range of female genital appearance, most clinicians used photos, diagrams and artworks, and some asked the patient to hold a mirror when being examined (1CS; 3G; 4G; 5G; 6G; 8G). Some adolescents find this reassuring: "there are some consultations where a young woman will have a look at the photos and go 'oh, thank goodness' ... and that might be the end of it" $(8 G)$, but some do not. Some young girls have not even wanted to look at the labial photos: "it's all 'yuck'” (8G).

There were mixed reports from participants on the 'success' of this strategy of reassurance about normal variation. Some patients are relieved, but some are not. According one gynaecologist:

... very often both - particularly the younger ones and the parents are very relieved and reassured to be told that they're normal. The ones that persist in saying 'well I don't like it', then that's a different story ... I would say that probably about fifteen to twenty percent of the girls I see would be in that category (4G).

Another commented that while she sees "the relief" on the faces of some patients, there are other situations where she has felt that the patient "probably left feeling worse than when she walked in the door" and that saying "oh, but this is normal" does not help some patients: "it's just minimising her complaint even more and I don't think that is okay" (8G).

One participant explicitly stated that reassuring patients they are normal misses the mark for patients whose concern is not about being normal:

...they just say specifically that I do not like the appearance, I don't like the way the labia stick out, that's their big thing, they don't like them sticking out. You get the odd one that talks about normal and abnormal but the vast majority, it's straight forward, they have a good idea of what they need and what they're 
requesting. They don't understand how we're going to get there but they know what the end result should be (11CS).

Some clinicians explained how they first try to understand the patient's concerns by listening to them (1CS; $8 \mathrm{G})$. One reported that before introducing the concept of diversity in genital appearance, she has no "preconceived" ideas of what she is going to do or say to the patient and she tries "not to judge" the patient (8G). She begins by listening to the young person, trying to understand what the patient is going through, both physically and emotionally.

Other initial responses included suggesting that the patient come back when older, if she still had concerns then. For example, a gynaecologist described the following interaction: "I said to her, you maybe need this surgery to make them even ... she was sixteen, not sexually active, I encouraged her to come back when she will be twenty and maybe sexually active and decide whether she really needs it or not" (7G).

Some clinicians suggested that an adolescent wanting her labia fixed is "a marker for something else going on" (9SH). The "something else" could be sexual abuse or bullying (9SH; 2G; 5G) and the clinician's response to a request for labioplasty entails working out what supports are needed for that particular patient, such as "sexual counselling"(9SH).

All clinicians in this study reported that if an adolescent was threatening suicide or self-harm, they would refer them for counselling or emergency psychiatric intervention.

\section{Considering Surgery}


Overall, three participants indicated that they had performed a labioplasty for an under 18-year-old. All others indicated that they were not in principle opposed to labioplasty in under 18-year-olds, with most specifying for functional/physical or abnormality reasons.

We asked clinicians what they are, or would be, trying to find out, to help them reach a decision about whether to do the procedure or not for their adolescent patients. There were a range of matters on which they wanted to explore and form a view on. These were:

- Whether the patient is seeking surgery or information: "are they really just after information and you can reassure them about normality ..." (9SH).

- What the patient's reason is for wanting surgery - what exactly are they concerned about?

- What the patient's motivation is - who is driving it, and is she doing it for herself or for others, such as a boyfriend who has made a disparaging remark? (11CS)

- What the patient's expectations of surgery are - are they realistic? (1CS; $3 G)$.

- Risk/benefit ratio; Do the benefits of the surgery outweigh the risks of doing the surgery: "What's the likelihood that I can improve their self-esteem without damaging them" (10PS).

- Whether the patient has tried other things. Suggestions included: "thick nappy rash cream” for chaffing or functional issues (5G); “... maybe not so tight clothing, maybe let some hair grow, if things are sticking put some Vaseline on and see if the surfaces won't stick, particularly if it's a nuisance when you're playing sport" (6G). The idea here is that these measures "buy 
time" because with time, the patient matures and things may "change enough that they no longer see a need" for surgery, e.g. "the labia majora may get bigger with time, so the labia minora might be less prominent" (6G).

The reason for the patient's request was a major factor in clinicians' decisions about whether or not to provide surgery. The main types of reasons reported by clinicians, and their implications for the decision about offering surgery, are as follows:

1. Purely appearance or "cosmetic" reasons with no abnormality. Almost all the participants would not do surgery for appearances concerns only. One stated that “... when people want to just change their appearance, I don't see that as a medical problem" (2G). Another framed absence of concern about appearance as an indication that surgery may well be justified: “... and I thought the request was very legitimate because it wasn't that she was just there with body image [concerns]..." (3G)

2. Abnormality in size or structure: "I don't do the surgery for plastic surgical reasons, so I would only do it if there is an abnormality (4G); “...everybody's asymmetrical so ... unless one's ridiculously abnormal, would not be an indication" (4G).

3. Physical symptoms: "I try to restrict surgery to where I believe that there's actually a physical problem, physical symptoms associated with the abnormality" (2G). The severity of these symptoms was important: "Is this something that's impacting on their life so much that they just can't do the normal things other young women can do?" (8G).

4. Psychological symptoms: "How much distress is it causing?" (5G). 
A number of clinicians specifically mentioned that they are seeking to confirm that the patient does not have Body Dysmorphic Disorder or an "underlying psychiatric problem" (1CS; 6G; 7G).

Clinicians reported that they described the risks of the procedure and feel sure that patients understood (1CS:2G;3G;4G;5G;6G;7G;10PS;11CS). Their own views about how risky it is varied. Some indicated that they saw labioplasty as a risky procedure:

... in children and adolescents ... if they're normal I wouldn't do the surgery. There's absolutely no doubt in my mind that the risks outweigh any benefits...(4G);

... if there's concern around self-harm then yeah, l'd be more likely to be swayed but it's just difficult because the reported rates of complications from these procedures are reasonably high, like up to a third chance of infection or scarring $(5 \mathrm{G})$;

... you can't predict who's going to have a sensitive scar and therefore that they might have pain in that area ... there are reports of loss of sexual function or loss of orgasm capacity (6G).

Others described labioplasty as not so risky:

... the risks, they're all fairly low ... it's not an involved or risky operation in a general sense ... it's not a big operation in terms of the amount of skin removed or the recovery ... (1CS)

... if done properly it's very easy, it's an area which heals nicely, technically easy ... with extremely low complication rate (7G).

Finally, medical indemnity insurance is also something that some clinicians take into account when deciding whether to do the surgery or not:

... my indemnity insurer issued a statement saying that they wouldn't backup any claims made for labioplasties performed by gynaecologists ... so that's one of the main reasons I wouldn't do it ... unless it's clearly medically indicated, which in these situations it usually isn't, I think you're leaving yourself really vulnerable (5G). 
Participants who spoke about this insurance issue were unable to say if significant psychological distress would count as a medical reason.

\section{Overall Reflections}

Some participants offered overall reflections about labioplasty in adolescents. The following reflection is from an adolescent gynaecologist in response to the question of whether she has any ethical concerns about FGCS in adolescents. Her concern is about operating on a girl with normal anatomy:

$\ldots$ at a time of their life where there is so much change and growth, and they're questioning their body - I don't know quite what the right word is, their body identity, the normality of their body which changes as they get older ... all teens go through that kind of 'I want to be perfect, I'm not perfect, I've got to be perfect.' But it's like a stage that they grow through and grow out of and it just seems that to do plastic surgery in that situation where that decision is going to change as time goes by is wrong. I think that in this situation, where it's purely plastic surgery, that making those kind of decisions at that age is probably not correct $(4 \mathrm{G})$

Another participant reflected on the broader social context including social norms about genital appearance:

... part of the problem is the unrealistic images that they have so they see these images of women with large, round breasts and no pubic hair and smooth labia and they think that they need to be like that ... that upsets me and disturbs me ... I guess it's a bigger question. Am I contributing to that by being in the industry that facilitates that, but I don't know, it's a sort of philosophical question I can't answer (1CS)

Another, a plastic surgeon, reflected on why people want cosmetic surgery and the strength of what motivates them: 
I think it's to improve their self-esteem. It's not to make them look more beautiful ... The next question is how strongly do people value their selfesteem? And the answer to that is more than life itself and I can tell you that because people with really poor self-esteem commit suicide. (10PS)

\section{Discussion}

Our findings suggest that clinicians are thinking in quite nuanced ways about how to manage requests from adolescents. They do think about normalcy and refer to the function/appearance distinction, in accordance with the literature and the guidelines. However, they also take into account a number of other considerations, which are more directly linked to fundamental ethical values in medicine.

Types of Patients

Our findings suggest that clinicians see patients are falling into two categories:

- Ones who can be reassured by explanations about normality - these patients could be called "desistors", because their desire for labioplasty ceases.

- Ones who stay concerned, despite attempts to reassure them. These patients could be called "persistors", because their desire for surgery continues.

When a patient is a "persistor", a number of key ethical factors were reported by our participants as needing to be taken into account. These include the reason for the patients' request, the level of risk and the patient's understanding of risk, whether there are feasible alternatives, how much the patient's anatomy, or their concern about it, is affecting their lives, and whether surgery could be beneficial in alleviating these effects. 
The type of reasons that adolescents gave for their concerns made an ethically significant difference to clinicians in how they responded. Some clinicians regarded concern that was solely about appearance as always ruling out surgery as an ethically acceptable option. However, other clinicians did not rule out in principle surgery for appearance-only concerns. Instead, they reported focusing on distress and the capacity of surgery to improve state of mind. As noted, one participant suggests that cosmetic surgery is about wanting to improve self-esteem and that people with really poor self-esteem sometimes commit suicide. When deciding whether to do surgery or not, this clinician did a risk/benefit assessment that included the psychological aspect of patients' self-esteem alongside the physical aspects of risk and benefit.

So whilst we agree with the emphasis placed on education and reassurance in current policy and clinical recommendations, we also suggest that an ethical and policy response must include the persistors - those who are not reassured by being told that they are normal. In this regard, it is important to consider further the distinction between functional and appearance concerns, which, as we noted earlier, is made in many professional guidelines and academic publications, and was also often referred to by our participants.

Investigating the Distinction Between Functional and Appearance Concerns. At least three aspects of the concept of appearance in relation to labia can be identified in our interview data :

- Large: “...they thought that they had really big bits and they were hideous ..." (2G) 
- Protruding: “... they just say specifically that I do not like the appearance, I don't like the way the labia stick out, that's their big thing, they don't like them sticking out." (11CS)

- Asymmetry: “... her look was completely asymmetrical” (7G)

Likewise, the term "functional" varied in the way it was used by our participants.

Possible meanings or examples of functional problems seemed to include:

- Discomfort and chaffing when doing activities: “... irritation, pain, burning, rubbing, interfering with the things they want to do ..." (8G)

- Discomfort / chaffing when wearing certain types of clothes: "...uncomfortable in clothes and couldn't wear tight jeans" (1CS)

- Something shows through clothes: “... functional, as in they're so big that they're visible in pants and uncomfortable in pants..." (10PS);

- The labia minora "interfere with urinary flow" (10PS)

As can be seen from the above, the distinction between function and appearance is fuzzy. There is confusion and overlap between what is a "functional" concern and what is an "appearance" concern. Some of the above examples of "functional" problems are just as much about appearance as they are about function: “... visible in pants ..." (10PS); "...couldn't wear tight jeans" (1CS). Similarly, asymmetry of the labia minora was seen by at least one of our participants as an appearance issue, but in an influential professional position statement (American College of Obstetricians and Gynecologists 2007) and in the medical literature (Liao, Taghinejadi, and Creighton 2012), asymmetry is presented a functional issue which provides a valid reason for surgery. 
The findings from our study indicate that the distinction between functional and appearance concerns is not clear and is not consistently used. The recent report from the Nuffield Council on Bioethics on cosmetic procedures also acknowledges this lack of clarity, and does not rely on the distinction in its conclusion (Nuffield Council on Bioethics 2017). We argue that the distinction is not just unclear but is actually ethically irrelevant. There are two reasons for this. The first is that, conceptually, the distinction is simply not clear enough to carry ethical weight: it cannot reliably distinguish between cases. The second reason is that even if it were conceptually clear, the distinction does not relate to a real value difference. That is, it is not connected to any fundamental value.

The fundamental value in medicine is promotion of health. We take the view that health should be interpreted broadly. It should include relieving psychological distress not just the restoration of physical function. It is not just about fixing physical abnormality. We do not see this view as controversial. In the broad WHO sense, relieving psychological distress is part of the proper role of medicine: "Health is a state of complete physical, mental and social well-being and not merely the absence of disease or infirmity" (World Health Organization 1948). The source or cause of distress is not the key issue. A person's distress may be influenced by her social context and prevailing norms, but still needs to be relieved. This is why we propose that there is no ethically relevant difference between appearance concerns and functional concerns. Both types of concern can diminish health and it is within the role of medicine to address both, in order to improve health. The method of managing distress for the individual is also not in itself ethically crucial. Drugs and surgery, along with talking therapies and advice about alternative and lifestyle style, 
are all in principle ethically legitimate. The most central and obvious example of this is relief from anxiety or depression with drugs and electroconvulsive therapy. Other examples of medicine's role in the relief of psychological distress by use of drugs and surgery include puberty suppression as treatment for an adolescent with Gender Dysphoria, and termination of pregnancy for reasons related to psychological distress or mental health of a pregnant woman (in jurisdictions which legally permit this).

In relation to the influence of social norms about genital appearance, medical professionals also have a role to play in educating the community about variations in genital appearance. In the long-run, this may attenuate some distress about genital appearance, but cannot be expected to eliminate it.

Is "Normality" Important?

Our participants referred to "normality" or "normal appearance", and many used this as a marker of whether or not surgery was warranted, separate from the degree of distress the patient was experiencing. This raises the question of what counts as "normal", and why "normality" should play such a defining role in decision-making about surgery. Earlier, we noted the preoccupation with what constitutes "normal" genital dimensions amongst those who worry about the increase in female genital cosmetic surgery (Harding et al. 2015; Royal Australian College of General Practitioners 2015; Runacres and Wood 2016). Indeed, the words "normal", "normality" or "abnormal" appear 37 times in Harding's short article about managing patients who are concerned about their genital appearance (Harding et al 2015). 
We have previously questioned this emphasis on normality (Spriggs and Gillam 2017,438 ) whether of structure or function. In doing so, we became aware of how entrenched this concept is. In a published response to our paper, Wood simply refuse to engage with our argument, simply re-stating the orthodoxy as if selfevident: "Dr Spriggs and Prof Gillam appear to miss the crucial importance of defining normality ..." (Wood 2017, 439).

Unreflective and Entrenched Positions

The findings from our interview study support our critique of the reliance on the concept of normalcy and functional/appearance distinction in the literature and policy documents. These concepts are not robust enough to do ethical work, and do not address fundamental ethical considerations about beneficence and non-maleficence. Our argument, then, is that the question about ethical justifiability of labioplasty turns on whether the procedure will be able to bring about sufficient benefit to justify any risks, when compared with any alternatives. Evidence that labioplasty is harmful does not exist as yet, as acknowledged by the UK Royal College of Obstetricians and Gynaecologists (RCOG Ethics Committee 2013, 6) and there are clear indications the standard reassurance approach does not always produce benefit. Our position implies that labioplasty could, in principle, be ethically justifiable for an adolescent patient with appearance concerns. We note that it also implies that labioplasty is not automatically justifiable for "functional" concerns.

We are aware that this is not an orthodox conclusion to reach. It has already been resisted by some, apparently for this reason. Wood, for example, asserts that: "For girls who still have major concerns after 'standard' reassurance then conservative 
supportive management should be advocated as the next ongoing line of treatment" (Wood 2017, 439). This is stated as if it were obvious and incontrovertible, not open for any question or reflection. No reason is given as to why surgery could never be considered. Even more vehement was the anonymous reviewer of a previous version of this paper, submitted to a different journal. That reviewer described our "approach" as "ethically unacceptable" and the guidance we offer as "ethically perilous". The reviewer relied on unsupported claims about the "potential for harm" if labioplasty were done when the source of the adolescent's concern was "not truly functional", and was simply unwilling to countenance any interpretation even slightly beyond the existing narrow parameters of the dominant position on labioplasty in adolescents.

Our position, though unorthodox, is not entirely without support. We note that we are not alone in suggesting unreflective and entrenched positions may need rethinking (Veal et al. 2014; Goldstein and Jutrzonka 2016; Goodman et al. 2016). Recent studies add to the evidence base for FGCS, indicating high rates of satisfaction, abatement of body-dissatisfaction and improvements in psychological well-being (Veale et al. 2014; Goodman et al. 2016; Sharp, Tiggeman, and Mattiske 2017). Questions have also been raised about the validity of concerns about complications, with lack of formal training cited as a major possible cause (Sharp, Tiggeman, and Mattiske 2017; Goodman 2017; Goodman et al. 2016; Goldstein and Jutrzonka 2016; Goodman et al. 2007)

\section{Conclusion}


Our empirical study involves a small volunteer sample from a single country. It cannot be taken as representative of the responses and reasoning of all clinicians who receive requests from adolescents for labioplasty. It does not prove that all, or even a determinable proportion, use concepts of normalcy and function/appearance distinction in their ethical reasoning, nor that some or all use other, more overtly ethical concepts, when the clinical situation seems to require more nuanced thinking. However, our extended interviews do indicate that for at least some clinicians, the orthodox approach does not adequately address the complexities of making ethical appropriate decisions for a patient sitting in front of them. This, combined with a critical analysis of the orthodox approach, gives sound reason to propose that more nuanced ethical guidance for clinicians is needed. We have three specific recommendations.

Our first recommendation is that policy and guidelines should recognise the "persistors" - those girls who remain concerned despite attempts to reassure them. There is a gap in current policy and guidelines in that they do not adequately address how to deal with these patients.

Our second recommendation is that policy and guidelines should not rely on the function / appearance distinction. Furthermore, the distinction should not be used as a basis for decisions relating to surgery for those adolescents whose concerns persist despite talk about the wide range of normal genital appearance. The focus of clinicians should be on relieving distress, whatever the cause, rather than categorising concerns as functional/physical or appearance, and hence legitimate or not legitimate. There is one policy document which touches on the relief of distress, but even that does not incorporate this into its recommendations. The 2016 
American College of Obstetricians and Gynecologists (ACOG), Committee on

Adolescent Health Care opinion on breast and labial surgery in adolescents does not limit consideration of surgery to abnormalities or disease. It allows persistent psychological or emotional concerns as a reason to consider surgery (ACOG 2016). We recommend that other policy documents take this position.

Our third recommendation relates to the type of reassurance given. In addition to, or instead of reassurance that a patient's genitals are normal, adolescents (even the "desistors") could also benefit from reassurance that it is normal to worry about their appearance, including the appearance of their genitals. The tendency of teenagers to worry about this was referred to by one of our informants:

... at a time of their life where there is so much change and growth, and they're questioning their body ... the normality of their body which changes as they get older ... all teens go through that kind of 'I want to be perfect, I'm not perfect, I've got to be perfect.' But it's like a stage that they grow through and grow out of ... (4G).

The 2016 ACOG Opinion which does not limit considerations of surgery to structural abnormalities or disease, also recognises the tendency for adolescents undergoing rapid transformation and growth under the influence of pubertal hormones to question whether their body is normal (ACOG 2016, e138) but does not mention this in its recommendations. We recommend this kind of reassurance; that it is normal for teenagers to worry about their appearance should be made explicit in guidelines on managing the concerns of adolescents.

Finally, we note the implications of focusing on relieving distress of patients with concerns about their genitals. This plays out in two ways: (i) appearance reasons may justify surgery (as we have argued previously (Spriggs and Gillam 2016)) and (ii) function reasons may not be sufficient to justify surgery. The latter point was 
highlighted by one of the clinicians we interviewed: “... boys have got a whole lot more stuff down there and they manage to ride a horse and bicycles really well" (4G). Social norms and context may lie behind functional as well as appearance issues.

\section{References}

American College of Obstetricians and Gynecologists. 2007. ACOG committee opinion No. 378: Vaginal "rejuvenation" and cosmetic vaginal procedures. Obstetrics and Gynecology 110(3): 737-738.

American College of Obstetricians and Gynecologists. 2016. ACOG committee opinion No. 662: Breast and labial surgery in adolescents. Obstetrics and Gynecology 127(5): e138-140.

American Society for Aesthetic Plastic Surgery. 2014a. Americans spent largest amount on cosmetic surgery since the great recession of 2008. Press Release. New York 2014. http://www.surgery.org/media/news-releases/theamerican-society-for-aesthetic-plastic-surgery-reports-americans-spentlargest-amount-on-cosmetic-surger\#.VP4eMpTaVIU.email. Accessed November 16, 2016.

American Society for Aesthetic Plastic Surgery. 2014b. 2013 Cosmetic Surgery National Data Bank Statistics. New York 2014. http://www.surgery.org/sites/default/files/Stats2013_4.pdf. Accessed November 16, 2016. 
American Society for Aesthetic Plastic Surgery. 2016. 2015 Cosmetic Surgery National Data Bank Statistics. Aesthetic Surgery Journal / The American Society For Aesthetic Plastic Surgery 36(Suppl 1): 1-29.

Australian Government. 2015. Medicare item reports. Item number 35533 (labioplasty).

http://medicarestatistics.humanservices.gov.au/statistics/mbs_item.jsp. Accessed September 28, 2015).

Berer, M. 2010. Labia reduction for non-therapeutic reasons vs. female genital mutilation: contradictions in law and practice in Britain. Reproductive Health Matters 18(35): 106-10.

Boraei, S., C. Clark, and L. Frith. 2008. Labioplasty in girls under 18 years of age: An unethical procedure? Clinical Ethics 3(1): 37-41.

Braun, V. 2009. Female genital cosmetic surgery: A critical review of current knowledge and contemporary debates. Journal of Women's Health 19(7): 1393-407.

British Society for Paediatric \& Adolescent Gynaecology. 2013. Position Statement. Labial reduction surgery (labiaplasty) on adolescents. http://www.britspag.org/sites/default/files/downloads/Labiaplasty\%20\%20final \%20Position\%20Statement.pdf. Accessed January 6, 2017.

Creighton, S. 2014. AGAINST: labiaplasty is an unnecessary cosmetic procedure. BJOG: An International Journal Of Obstetrics And Gynaecology 121(6): 768.

Deans, R., L-M Liao, N.S. Crouch and S.M. Creighton. 2011. Why are women referred for female genital cosmetic surgery? Medical Journal of Australia 195(2): 99-99. 
Dorneles de Andrade, D. 2010. On norms and bodies: Findings from field research on cosmetic surgery in Rio de Janeiro, Brazil. Reproductive Health Matters 18(35): 74-83.

Goldstein, A.T., and S.L. Jutrzonka. 2016. Ethical considerations of female genital plastic/cosmetic surgery. In Female genital plastic and cosmetic surgery, edited by M.P. Goodman, 39-44. Oxford: Wiley-Blackwell.

Goodman, M.P., G. Bachman, and G. Johnson, et al. 2007. Is elective vulvar plastic surgery ever warranted, and what screening should be conducted preoperatively? Journal of Sexual Medicine 4:269-76.

Goodman, M. P. 2011. Female genital cosmetic and plastic surgery: A review. Journal of Sexual Medicine 8(6): 1813-1825.

Goodman, M.P., O.J. Placik, D.L. Matlock, et al. 2016. Evaluation of body image and sexual satisfaction in women undergoing female genital plastic/cosmetic surgery. Aesthetic Surgery Journal 36(9):1048-1057.

Goodman, M.P. 2017. Commentary on: A retrospective study of the psychological outcomes of labiaplasty. Aesthetic Surgery Journal 37(3):332-336.

Hamori, C.A. 2016. Teen labiaplasty: A response to the May 2016 American College of Obstetricians and Gynecologists (ACOG) recommendations on labiaplasty in adolescents. Aesthetic Surgery Journal 36(7):807-809.

Hansen, E. C. 2006. Successful qualitative health research. Crows Nest, New South Wales, Australia: Allen \& Unwin.

Harding, T., J. Hayes, M. Simonis, and M. Temple-Smith. 2015. Female genital cosmetic surgery: Investigating the role of the general practitioner. Australian Family Physician 44(11): 822-825. 
Jothilakshmi, P. K., N. R. Salvi, B. E. Hayden, and B. Bose-Haider. 2009. Labial reduction in adolescent population-A case series study. Journal of Pediatric and Adolescent Gynecology 22(1): 53-55.

Kelly, B., and C. Foster. 2012. Should female genital cosmetic surgery and genital piercing be regarded ethically and legally as female genital mutilation? BJOG: An International Journal Of Obstetrics And Gynaecology 119(4): 389-392.

Liao, L-M., and S. M. Creighton. 2007. Requests for cosmetic genitoplasty: How should healthcare providers respond? British Medical Journal 334(7603): 1090-1092.

Liao, L-M., L. Michala, and S. M. Creighton. 2010. Labial surgery for well women: A review of the literature. BJOG: An International Journal Of Obstetrics And Gynaecology 117(1): 20-25.

Liao, L-M., N. Taghinejadi, and S.M. Creighton. 2012. An analysis of the content and clinical implications of online advertisements for female genital cosmetic surgery. BMJ Open 12;2(6):pii: e001908.

Lloyd, J., N. S. Crouch, C. L. Minto, L-M. Liao, and S. M. Creighton. 2005. Female genital appearance: 'Normality' unfolds. BJOG: An International Journal Of Obstetrics And Gynaecology 112(5): 643-646.

Lynch, A., M. Marulaiah, and U. Samarakkody. 2008. Reduction labioplasty in adolescents. Journal of Pediatric and Adolescent Gynecology. 21(3): 147-149.

Manning, P., and B. Cullum-Swan. 1994. Narrative, content and semiotic analysis. In Handbook of qualitative research, edited by N. Denzin and Y. Lincoln, 463477. Thousand Oaks, CA: Sage. 
McQuillan, S. K., Y. L. Jayasinghe, and S.R. Grover. 2014. Audit of referrals for labial appearance concerns at the Royal Children's Hospital Melbourne: From 2000 onwards. Journal of Pediatric and Adolescent Gynecology 27(2): e60.

Medical Board of Australia. 2015. Public consultation paper and regulation impact statement. Provision of cosmetic medical and surgical procedures by registered medical practitioners. http://www.medicalboard.gov.au/News/PastConsultations/Consultations-March-2015.aspx. Accessed April 27, 2015.

Michala, L., S. Koliantzaki, and A. Antsaklis. 2011. Protruding labia minora: abnormal or just uncool? Journal Psychosomatic Obstetrics \& Gynecology 32(3): 154156.

National Health and Medical Research Council, Australian Research Council, and Australian Vice-Chancellors' Committee. 2007 updated May 2015. National Statement on Ethical Conduct in Human Research. Canberra: Commonwealth of Australia.

Nuffield Council on Bioethics. 2017. Cosmetic procedures: ethical issues. http://nuffieldbioethics.org/project/cosmetic-procedures. Accessed 10 July 2017.

Reddy, J., and M. Laufer. 2011. Labiaplasty: Surgical correction in adolescents. The Female Patient 36(4): 5-53.

Royal Australian College of General Practitioners. 2015. Female genital cosmetic surgery - A resource for general practitioners and other health professionals. http://www.racgp.org.au/your-practice/guidelines/female-genital-cosmeticsurgery/. Accessed November 16, 2016.

Royal College of Obstetricians \& Gynaecologists Ethics Committee. 2013. Ethical opinion paper: Ethical considerations in relation to Female Genital Cosmetic 
Surgery (FGCS).

https://www.rcog.org.uk/globalassets/documents/guidelines/ethics-issuesand-resources/rcog-fgcs-ethical-opinion-paper.pdf. Accessed August 22, 2016.

Runacres, S. A., and P. L. Wood. 2016. Mini-review: Cosmetic labiaplasty in an adolescent population. Journal of Pediatric and Adolescent Gynecology 29(3): 218-22.

Runacres, S., J. Hayes, S. Grover, and M. Temple-Smith. 2015. Do I need labiaplasty? The use of cadaver measurements in the search for normal vulval dimensions. E-Posters. BJOG: An International Journal Of Obstetrics And Gynaecology 122: 13-14.

Sharp, G., M. Tiggemann, and J. Mattiske. 2017. A retrospective study of the psychological outcomes of labiaplasty. Aesthetic Surgery Journal 37(3):324331.

Society of Obstetricians and Gynaecologists of Canada. 2013. SOGC policy statement: Female genital cosmetic surgery. Journal of Obstetrics \& Gynaecology Canada 35(12):1108-1112.

Spriggs, M., and L. Gillam. 2016. Body Dysmorphic Disorder: Contraindication or ethical justification for Female Genital Cosmetic Surgery in adolescents. Bioethics 30(9): 706-713.

Spriggs, M. 2016. Parent-led request for female genital cosmetic surgery in an adolescent. In When doctors and parents disagree: Ethics, paediatrics and the Zone of Parental Discretion, edited by R. McDougall, C. Delany and L. Gillam, 227-243. Sydney: The Federation Press. 
Spriggs, M., and L. Gillam. 2017. Cosmetic Labiaplasty: Defining "Normality" Is Not the Issue. Journal of Pediatric and Adolescent Gynecology 30(3): 438.

Strauss, A., Corbin, J. 1990. Basics of qualitative research: Grounded theory procedures and techniques. Newbury Park, CA: Sage.

The Royal Australian and New Zealand College of Obstetricians and Gynaecologists. 2015 amended July 2016. Vaginal 'rejuvenation' and cosmetic vaginal procedures C-Gyn 24. https://www.ranzcog.edu.au/collegestatements-guidelines.html. Accessed August 15, 2016.

Tong, A., P. Sainsbury, and J. Craig. 2007. Consolidated criteria for reporting qualitative research (COREQ): A 32-item checklist for interviews and focus groups. International Journal for Quality in Health Care 19(6): 349-357.

Ulrich, C. M., and S. J. Ratcliffe. 2008. Hypothetical vignettes in empirical bioethics research. In Empirical Methods for Bioethics: A Primer (Advances in Bioethics, Volume 11), edited by L. Jacoby, and L. Siminoff, 161-181. Emerald Group Publishing Limited.

Veale, D., I. Naismith, E. Eshkevari, et al. 2014. Psychosexual outcome after labiaplasty: a prospective case-comparison study. International Urogynecology Journal 25(6):831-839.

World Health Organization (WHO). 1948. WHO definition of health. http://www.who.int/about/definition/en/print.html. Accessed November 16, 2016.

Wood, P. 2017. Author's Response. Journal of Pediatric and Adolescent Gynecology 30(3): 439 . 
